\title{
Frequency of Benign Variants Associated with Hematologic Malignancy in the Catalogue of Somatic Mutations in Cancer
}

\author{
Kyoung-Jin Park ${ }^{1 \oplus}$ and Jong-Ho Park ${ }^{2}$ \\ ${ }^{1}$ Department of Laboratory Medicine, Myongji Hospital, Hanyang University College of Medicine, Goyang; 2Department of \\ Laboratory Medicine, Samsung Medical Center, Seoul, Korea
}

\section{Corresponding author:}

Kyoung-Jin Park

Department of Laboratory Medicine, Myongji Hospital, Hanyang University College of Medicine, 55 Hwasu-ro 14 beon-gil, Deogyang-gu, Goyang 10475, Korea

Tel +82-31-810-7082

E-mail unmar21@gmail.com

Received: October 17, 2020

Revised: November 10, 2020

Accepted: November 16, 2020
This is an Open Access article distributed under the terms of the Creative Commons Attribution Non-Commercial License (http://creativecommons.org/licenses/ by-nc/4.0) which permits unrestricted non-commercial use, distribution, and reproduction in any medium, provided the original work is properly cited.
Background: The presence of benign variants in mutation databases is a well-documented pitfall when interpreting clinical variants associated with hematologic malignancy. The aim of this study was to investigate the frequency of benign or likely benign (B/LB) variants associated with hematologic malignancy in the Catalogue of Somatic Mutations in Cancer (COSMIC), which is one of the most commonly used databases for cancer.

Methods: A total of $12,149,816$ coding variants were downloaded from COSMIC (release ver. 91, April 2020), and 123,211 variants in 99 genes associated with hematologic malignancy were analyzed. The genes were selected according to the criteria recommended by the World Health Organization and National Comprehensive Cancer Network guidelines. The variant classification was performed based on standardized interpretation guidelines.

Results: The frequency of $B / L B$ variants was $3.2 \%(3,890 / 123,211)$ of the COSMIC variants. In addition, $44.9 \%(1,748 / 3,890)$ of $B / L B$ variants were observed in at least two cancer samples. In terms of drug response and cancer susceptibility, $2.9 \%(112 / 3,890)$ of the B/LB variants were clinically significant.

Conclusions: This study revealed that a significant number of $B / L B$ variants were registered in COSMIC. This study highlights the importance of the reinterpretation of cancer variants reported from mutation databases and could be a good starting point for an in-depth review of somatic mutations essential for precision oncology.

(Lab Med Qual Assur 2021;43:25-30)

Key Words Catalogue of Somatic Mutations in Cancer, Database, Mutation

\section{서론}

혈액종양에서 발견되는 체세포 돌연변이(somatic mutation) 의 정확한 분류 및 해석은 혈액종양의 진단, 치료 및 예후 예측 에 매우 중요하다. 임상적으로 유의미한 체세포 돌연변이는 암 유발 돌연변이(driver mutation)로 분류되는데, 이는 양성 변이 (benign variant) 또는 승객 돌연변이(passenger mutation)
와의 구별이 쉽지 않다. 임상유전검사실에서 체세포 돌연변이를 해석할 때 주로 Catalogue of Somatic Mutations in Cancer (COSMIC)를 주로 참고하며, 이 외에도 Precision Oncology Knowledge Base, Clinical Interpretation of Variants in Cancer (CIViC), Database of Evidence for Precision Oncology, Cancer Genome Interpreter 등을 포함한 종양 데 이터베이스를 다양하게 활용하고 있다[1-5]. 그런데 COSMIC에는 
양성 변이가 상당수 포함되어 있으며, 이는 체세포 돌연변이의 해 석을 어렵게 하는 주요 요인이 될 수 있다.

체세포 돌연변이 해석을 위한 데이터베이스의 의존도가 높음 에도 불구하고, COSMIC에 양성 변이가 얼마나 많이 포함되어 있 는지에 대해서는 보고된 바 없다. 더구나 최근 국내 임상검사실에 서도 혈액종양의 진단, 치료, 예후 예측을 위해 대용량염기서열분 석법의 이용이 증가되면서, 종양 데이터베이스에 등록된 돌연변 이 분류의 중요성은 더욱 강조되고 있다. COSMIC 데이터베이스 에 등록된 양성 변이의 빈도를 확인하고, 돌연변이를 정확하게 재 분류하는 작업은 돌연변이 해석의 정도관리에서 중요한 부분이며, 임상유전자검사 보고서의 정확도 향상을 위해 필수적이다.

이에 본 연구에서는 COSMIC에 등록된 양성 변이의 빈도를 평 가하고자 한다. 이를 통해 종양 데이터베이스의 사용의 신뢰도를 증가시킬 수 있으며, 이는 혈액종양 임상유전자검사의 정도관리 측면에서도 중요하다. 또한 COSMIC에 등록된 양성 변이 리스트 를 확보하고 이를 통해 체세포 돌연변이의 분류 및 보고의 정확도 를 향상시킴으로써 혈액종양의 진단, 치료, 예후 예측을 위한 임상 유전자검사의 정도관리에 기여하고자 한다.

\section{재료 및 방법}

COSMIC (release ver. 91, 7th April 2020, VCF/Cosmic CodingMuts.vcf.gz; https://cancer.sanger.ac.uk/cosmic/, download on May 2020)에 등록된 $12,149,816$ 개의 변이 를 다운로드 받아 혈액종양 임상유전자검사에 중요한 유전자에 서 발생하는 123,211 개의 변이를 분석하였다. 99 종의 연구대 상 유전자는 보건복지부 고시 필수 유전자 24종(ASXL1, BRAF, CALR, CEBPA, CSF3R, DNMT3A, FLT3, IDH1, IDH2, IKZF1, JAK2, KIT, KRAS, MPL, MYD88, NPM1, NRAS, RB1, RUNX1,
SETBP1, SF3B1, SRSF2, TET2, TP53), 혈액종양 진단을 위 해 세계보건기구(World Health Organization) 가이드라인에 서 권고하는 유전자 41종( $A B L 1, A B L 2, A N K R D 26, B C R, C B F B$, CBL, CDKN2A, CDKN2B, CRLF2, CSF1R, DDX41, DEK, EBF1, ETNK1, ETV6, EZH2, FGFR1, FIP1L1, GATA2, IL3, KMT2A, MECOM, MKL1, MLLT3, MYH11, NF1, NOTCH1, NTRK3, NUP214, PBX1, PCM1, PDGFRA, PDGFRB, PML, PTPN11, RARA, RBM15, RUNX1T1, TCF3, TYK2, U2AF1), 미국종합암네 트위크(National Comprehensive Cancer Network) 가이드라 인과 유럽백혈병네트워크(European LeukemiaNet) 권고사항 에 포함된 유전자 34종(ALK, ATM, BCL2, BCL6, BCOR, BIRC3, CCND1, DHX15, DKC1, EP300, GATA3, IL7R, JAK1, JAK3, KDM6A, MGA, MTCP1, MYC, PHF6, PRPF8, RAD21, SH2B3, SMC1A, SMC3, STAG2, STAT3, TAL1, TERC, TERT, TLX1, $T L X 3, W T 1, Z B T B 7 A, Z R S R 2)$ 을 포함한다[6-9].

전체 연구대상 변이에 대해 ANNOVAR를 이용하여 인구집단 데이터베이스(Single Nucleotide Polymorphism Database 인 dbSNP, 1,000 genome project, Exome Sequencing Project-6500 [ESP6500], The Genome Aggregation Database [gnomAD], Korean Reference Genome Database [KRGDB]), 전장유전체연관분석(genome-wide association studies, GWAS) catalog, 돌연변이 데이터베이스(Human Genome Mutation Database [HGMD], ClinVar, CIViC), in silico 예측 알고리즘(sorting intolerant from tolerant [SIFT], polymorphism phenotyping-2 [PolyPhen], LRT, FATHMM, MutationTaster, MutationAssesor, PROVEN, MetaSVM, and M-CAP, MetaLR, CADD, DANN, GERP) 데이터를 주석으로 더해 주었다[10].

미국의학유전학회(American College of Medical Genetics

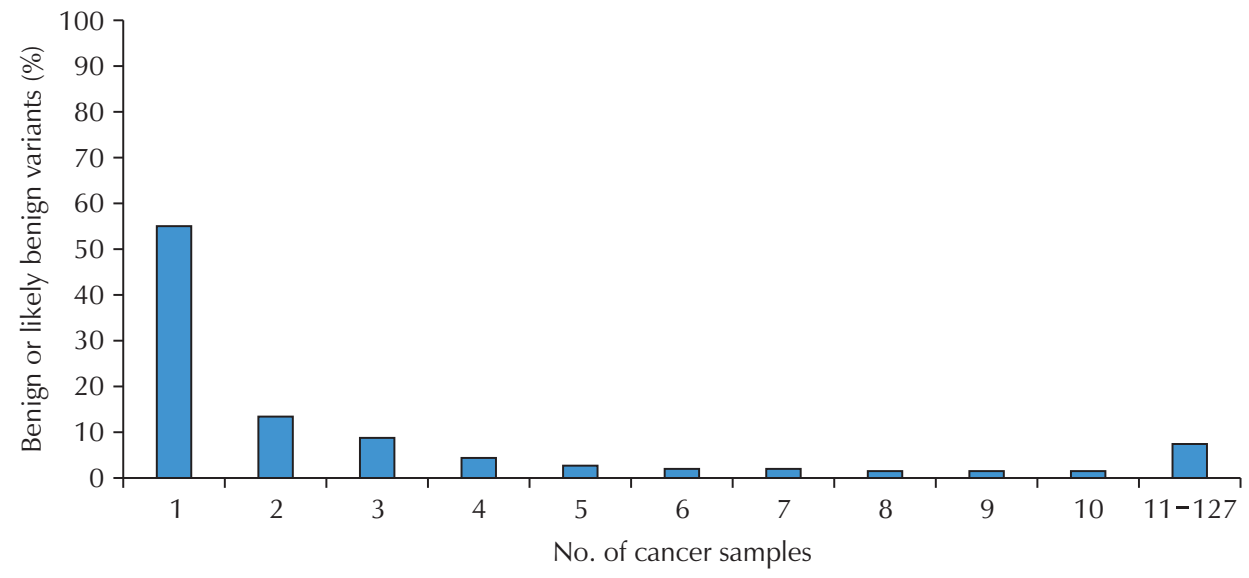

Fig. 1. Frequency of benign or likely benign variants. 


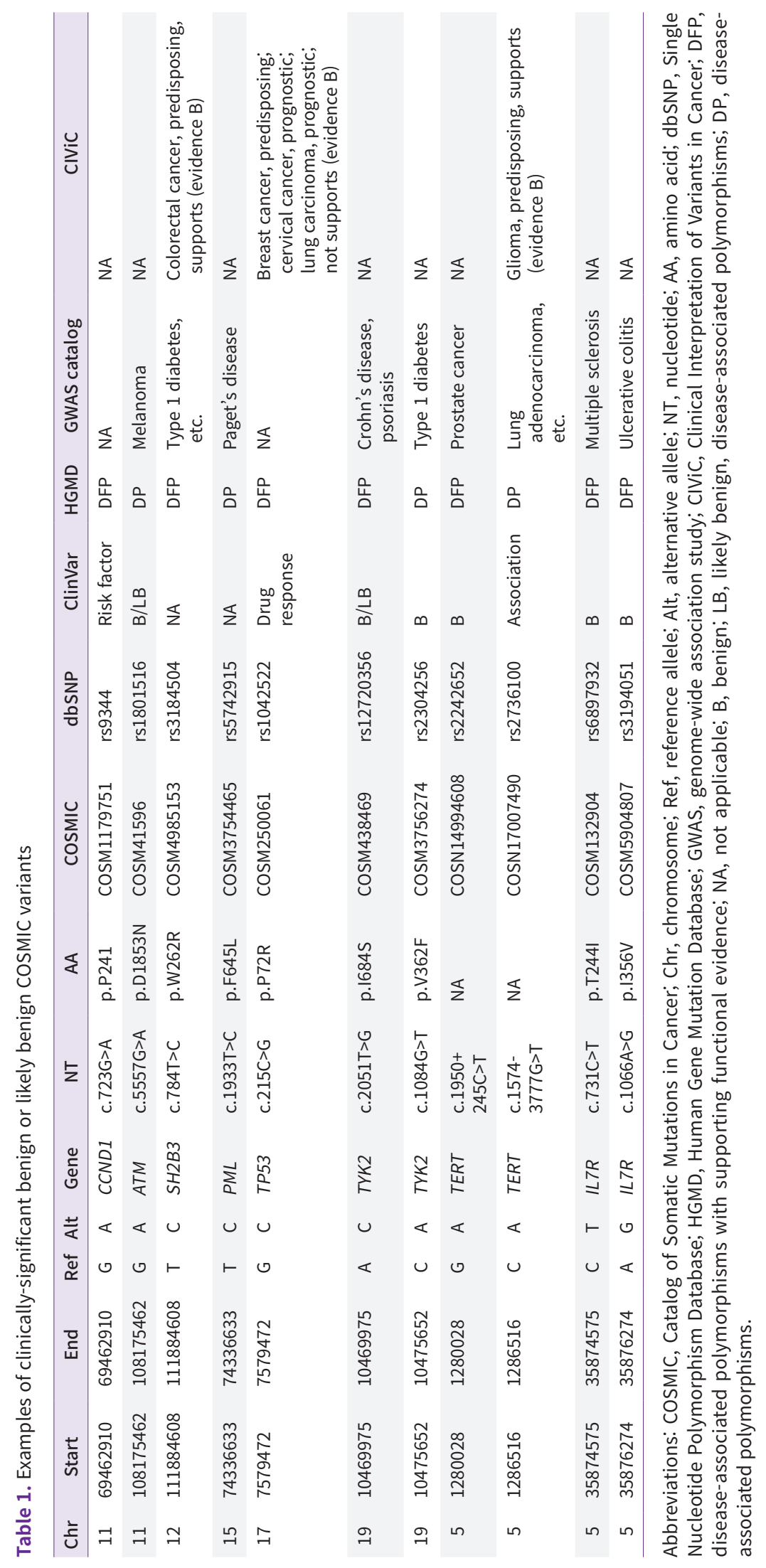


and Genomics, ACMG)와 분자병리학회(Association for Molecular Pathology, AMP)에서 2015년에 발간한 ACMG/ AMP 가이드라인에 따라 대립유전자빈도(minor allele frequency)가 5\%를 초과하는 모든 변이를 양성 변이로 분류 하였다[11]. 또한 minor allele 빈도가 $5 \%$ 이하인 변이 중에 서 ClinVar에서 "benign" 또는 "likely benign"으로 보고되 고 HGMD에서 disease-associated polymorphisms (DP), disease-associated polymorphisms with supporting functional evidence (DFP), in vitro or in vivo functional polymorphism (FP) 등으로 분류한 변이도 양성 변이로 선별 후, $\mathrm{ACMG} / \mathrm{AMP}$ 가이드라인에 기반하여 양성 변이를 분류하였다. 약 물반응 예측 및 종양에 대한 감수성, 표현형과의 연관성 등의 측면 에서 선별한 양성 변이의 임상적 의미를 재평가하였다.

\section{결과}

혈액종양과 관련된 COSMIC 유전변이 123,211 개 중에서 양 성 변이의 빈도는 $3.2 \%(3,890 / 123,211)$ 로 확인되었다. 이 중 $44.9 \%(1,748 / 3,890)$ 의 양성 변이는 종양 검체에서 반복적으 로 보고되는 양성 변이에 해당한다(Fig. 1). 3,890개의 양성 변 이 중 1,367 개의 변이가 ClinVar에서 보고된 바 있는 변이이며, 99.8\% (1,353/1,367) 양성 변이가 ClinVar에서도 "benign" 또 는 "likely benign"으로 보고되었다. 반면, 3,890개의 양성 변이 중 76 개의 변이는 HGMD에서도 보고된 바 있는 변이이며, 28 개 의 양성 변이만이 HGMD에서 DP, DFP, FP로 보고되었고, 48 개 의 양성 변이는 HGMD에서 disease-causing mutations (DM) 으로 보고되었다.

혈액종양과 관련된 COSMIC 양성 변이 중에서 임상적으로 유 의미한 변이(clinically-significant polymorphism)의 빈도는 $2.9 \%$ ( $n=112 / 3,890)$ 로 확인되었다. 특히 11 개의 변이는 여러 데 이터베이스에서 약물반응 예측 또는 질환 관련성 측면에서 임상적 으로 유의미한 양성 변이로 보고된 바 있다(Table 1).

\section{고찰}

AMP, 미국임상종양학회(American Society of Clinical Oncology, ASCO), 미국병리학협회(College of American Pathologist, CAP)에서 2017년에 발간한 AMP/ASCO/CAP 가 이드라인에 따르면, 종양에서 발견되는 체세포 돌연변이는 임상 적 영향력에 따라 4 tier 시스템으로 보고되어야 한다[12]. 가이 드라인, 전문가 의견, 임상시험, 전임상시험 결과에 근거를 두고, 강력한 임상적 중요성이 있는 변이를 tier I, 잠재적 임상적 중요
성이 있는 변이를 tier II, 임상적 중요성이 알려져 있는 않은 변 이를 tier III, 양성 또는 양성으로 추정되는 변이를 tier IV로 구분 하도록 하고 있다[12]. 이 중 tier IV 변이는 대부분 생식세포변이 (germline variant)일 가능성이 높으며, 이론적으로는 50\% 또 는 $100 \%$ 의 대립유전자빈도(variant allele frequency)를 보인 다. 또한 생식세포변이는 $\mathrm{ACMG} / \mathrm{AMP}$ 가이드라인에 따라 병원 성 변이(pathogenic variant), 병원성으로 추정되는 변이(likely pathogenic variant), 병원성이 불명확한 변이(variant of unknown significance), 양성으로 추정되는 변이(likely benign variant), 양성 변이(benign variant) 5 단계로 분류된다[11].

종양 돌연변이검사가 의뢰될 때, 종양-정상 조직을 쌍으로 이루 는 검체검사를 시행하여 생식세포변이를 제외한 후, 임상적 중요 도에 따라 체세포 돌연변이를 분류할 것을 권장하지만, 실제 임상 에서는 정상 조직을 포함한 검체검사를 시행하기 어려운 상황이 대부분이다. 이에 임상유전검사실에서는 인구집단 데이터베이스, 돌연변이 데이터베이스, in silico 예측 알고리즘, 문헌고찰 등을 활용하여 변이의 임상적 중요성을 판단하고 있다. 따라서 변이해 석을 위한 표준 가이드라인 정립과 더불어 임상에서 자주 활용하 는 데이터베이스의 정확도가 필수적으로 요청된다.

본 연구에서는 혈액종양 유전자검사 보고서 작성 시 체세포 돌 연변이 데이터베이스로 가장 널리 이용하는 COSMIC에 포함된 양 성 변이의 빈도를 평가하였으며, 혈액종양 관련 양성 또는 양성으 로 추정되는 변이의 빈도를 $3.2 \%$ 로 확인하였다. 특히 종양 검체 에서 반복적으로 보고되는 COSMIC 변이의 $44.9 \%$ 는 양성 또는 양성으로 추정되는 변이로 확인되므로, 다양한 암종에서 고빈도로 보고된 체세포 돌연변이라도 종양 돌연변이검사 결과보고 시 주의 가 필요하다(Fig. 1).

또한 혈액종양과 관련된 COSMIC 양성 변이의 대부분이 ClinVar에서는 benign 또는 likely benign으로 분류된 반면, $\mathrm{HGMD}$ 에서는 대부분이 질환의 원인 돌연변이인 DM으로 분류되 어 있음을 확인하였다. 최근 연구에 따르면 임상적으로 널리 이 용되는 HGMD와 ClinVar의 변이 분류결과에 오류가 존재하며, ClinVar와 HGMD 데이터베이스 간 변이 분류 일치도는 $97.6 \%$ 로 보고되었다[13]. 체세포 돌연변이의 보고 및 해석 시, 생식세 포변이의 혼재 가능성을 고려하여 COSMIC 이외에도 HGMD, ClinVar, CIViC 등을 포함한 다양한 돌연변이 데이터베이스와 인 구집단 데이터베이스를 상호참조하고, 각 데이터베이스의 한계를 이해하는 것이 중요할 것이다.

본 연구에서 양성 또는 양성으로 추정되는 변이의 $2.9 \%$ $(112 / 3,890)$ 는 약물반응, 종양 감수성, 질환 연관성 측면 에서 임상적으로 유의미한 단일염기서열다형성(single nucleotide polymorphism)으로 확인되었다. 예를 들어 TP53 
c.215C>G (p.Pro72Arg) 변이(COSM250061)은 ClinVar에 "drug response (reviewed by expert panel)" 연관 변이 로 등록되어 있으며, 유방암, 난소암, 위암 환자에서 cisplatin, cyclophosphamide, fluorouracil, paclitaxel 등 함암제의 효능 및 부작용 예측에 활용할 수 있는 변이이며, 폐선암(lung adenocarcinoma) 관련 DFP로 HGMD에 등록되어 있는 변이다 (Table 1). 반면, 이 변이와 유방암 감수성, 자궁경부암의 예후, 폐 선암의 예후 관련성을 분석한 연구 등에서는 연관성이 없음을 시 사하는 데이터가 CIViC에 등록되어 있다(증거수준 B) (Table 1). 이 변이는 ACMG/AMP 가이드라인과 AMP/ASCO/CAP 가이드라 인을 적용할 때는 양성 변이 또는 tier IV 변이로만 분류되는 변이 로 임상적으로 간과되기 쉬운 변이에 속한다. 혈액종양에서 이 양 성 변이의 임상적 중요성이 확립된 것은 아니지만, 약물 용도변경 (drug repositioning)을 통한 적응증 확대와 종양의 종류를 불문 하는 암치료법(tumor-agnostic therapy)이 점차 확대되는 추세 를 반영할 때, 추후에는 이러한 양성 변이의 임상보고의 필요성이 점차 증대될 것이다.
본 연구에서는 데이터베이스 사용의 신뢰도를 증가시키기 위해 COSMIC에 포함된 양성 변이의 빈도를 평가하였으며, 양성 변이 의 임상적 의미를 재평가하였다. 체세포 돌연변이를 분류하고 해 석할 때 다양한 데이터베이스를 동시에 적용함으로써, 변이의 임 상적 의미를 정확하게 파악할 수 있었다. 향후 임상적으로 유의미 한 양성 변이의 임상보고를 위한 가이드라인의 정립이 필요할 것 으로 생각된다.

\section{감사의 글}

이 연구는 대한임상검사정도관리협회의 2020년도 학술연구과 제 연구비 지원으로 수행되었다(과제번호: 2020-07).

\section{ORCID}

Kyoung-Jin Park https://orcid.org/0000-0002-1262-6815 Jong-Ho Park https://orcid.org/0000-0001-5883-8322

\section{REFERENCES}

1. Tate JG, Bamford S, Jubb HC, Sondka Z, Beare DM, Bindal N, et al. COSMIC: the Catalogue of Somatic Mutations in Cancer. Nucleic Acids Res 2019;47(D1):D941-7.

2. Chakravarty D, Gao J, Phillips SM, Kundra R, Zhang H, Wang J, et al. OncoKB: a precision oncology knowledge base. JCO Precis Oncol 2017;2017:PO.17.00011.

3. Griffith M, Spies NC, Krysiak K, McMichael JF, Coffman AC, Danos AM, et al. CIViC is a community knowledgebase for expert crowdsourcing the clinical interpretation of variants in cancer. Nat Genet 2017;49:170-4.

4. Sun SQ, Mashl RJ, Sengupta S, Scott AD, Wang W, Batra P, et al. Database of evidence for precision oncology portal. Bioinformatics 2018;34:4315-7.

5. Tamborero D, Rubio-Perez C, Deu-Pons J, Schroeder MP, Vivancos A, Rovira A, et al. Cancer Genome Interpreter annotates the biological and clinical relevance of tumor alterations. Genome Med 2018;10:25.

6. Swerdlow SH, Campo E, Harris NL, Jaffe ES, Pileri SA, Stein H, et al. WHO classification of tumours of haematopoietic and lymphoid tissues. 4th ed. Lyon: International Agency for Research on Cancer, 2017.

7. Dohner H, Estey E, Grimwade D, Amadori S, Appelbaum FR, Buchner T, et al. Diagnosis and management of AML in adults: 2017 ELN recommendations from an international expert panel. Blood 2017;129:424-47.

8. Heidel FH, Gale RP, Hochhaus A. Managing myeloproliferative neoplasms evidence based on the ELN treatment recommendations 2018. Leukemia 2018;32:1055-6.

9. National Comprehensive Cancer Network. NCCN guidelines. https://www.nccn.org/professionals/physician_gls/ default.aspx (Accessed May 20, 2020).

10. Liu X, Wu C, Li C, Boerwinkle E. dbNSFP v3.0: a one-stop database of functional predictions and annotations for human nonsynonymous and splice-site SNVs. Hum Mutat 2016;37:235-41.

11. Richards S, Aziz N, Bale S, Bick D, Das S, Gastier-Foster J, et al. Standards and guidelines for the interpretation of sequence variants: a joint consensus recommendation of the American College of Medical Genetics and Genomics 
and the Association for Molecular Pathology. Genet Med 2015;17:405-24.

12. Li MM, Datto M, Duncavage EJ, Kulkarni S, Lindeman NI, Roy S, et al. Standards and guidelines for the interpretation and reporting of sequence variants in cancer: a joint consensus recommendation of the Association for Molecular Pathology, American Society of Clinical Oncology, and College of American Pathologists. J Mol Diagn 2017;19:4-23.

13. Park KJ, Lee W, Chun S, Min WK. The frequency of discordant variant classification in the human gene mutation database: a comparison of the American College of Medical Genetics and Genomics Guidelines and ClinVar. Lab Med 2020 Sep 14 [Epub]. https://doi.org/10.1093/labmed//maa072. 